\title{
Fluxos turísticos entre os países do Corrredor Bioceânico
}

\section{Tourism flows between the countries of the Biocean Highroad Crossing}

\author{
Flujos turísticos entre los países de la Corredor Bioceánico
}

\author{
Michel Constantino ${ }^{1}$ \\ Arlinda Cantero Dorsa ${ }^{1}$ \\ João Carlos Medeiros de Aragão ${ }^{2}$ \\ Dany Rafael Fonseca Mendes²
}

Recebido em 17/11/2018; revisado e aprovado em 18/01/2019; aceito em 01/06/2019

DOI: http://dx.doi.org/10.20435/inter.v20iespecial.2255

\begin{abstract}
Resumo: O objetivo do presente artigo foi de analisar o fluxo de turistas entre os países da Rota Bioceânica. Neste estudo, uma análise quantitativa foi utilizada para investigar a demanda internacional de turismo entre o Brasil, Argentina, Paraguai e Chile. Como a Rota Bioceânica ainda é uma aspiração em construção, a literatura é escassa e esse estudo se apresenta como pioneiro. Os resultados indicam que as variáveis tradicionais de demanda, chegada de turistas, formas de viagem, eventos internacionais e chegadas em Mato Grosso do Sul apresentaram um panorama geral do fluxo, que se revela incipiente e com pouca integração entre os países. A criação da Rota Bioceânica pode contribuir para o desenvolvimento dos países, principalmente na área de turismo que é dinâmico e crescente no mundo, e ainda pouco explorado na América do Sul.
\end{abstract}

Palavras-chave: corredor bioceânico; análise estatística; turismo; desafios do corredor.

Abstract: The objective of this article was to analyze the flow of tourists among the countries of the Bioceanic Route. In this study, a quantitative analysis was used to investigate the international demand for tourism between Brazil, Argentina, Paraguay and Chile. As the Bioceanic Route is still an aspiration under construction, literature is scarce and this study presents itself as a pioneer. The results indicate that the traditional variables of demand, arrival of tourists, forms of travel, international events and arrivals in Mato Grosso do Sul presented an overview of the flow, which is incipient and with little integration between countries. The creation of the Bioceanic Route can contribute to the development of countries, especially in the area of tourism that is dynamic and growing in the world, and still little explored in South America.

Keywords: bioceanic highroad crossing; statistical analysis; tourism; route challenge.

Resumen: El objetivo del presente artículo fue analizar el flujo de turistas entre los países de la Ruta Bioceánica. En este estudio, un análisis cuantitativo fue utilizado para investigar la demanda internacional de turismo entre Brasil, Argentina, Paraguay y Chile. Como la Ruta Bioceánica todavía es una aspiración en construcción, la literatura es escasa y ese estudio se presenta como pionero. Los resultados indican que las variables tradicionales de demanda, llegada de turistas, formas de viaje, eventos internacionales y llegadas en Mato Grosso do Sul presentaron un panorama general del flujo, que se revela incipiente y con poca integración entre los países. La creación de la Ruta Bioceánica puede contribuir al desarrollo de los países, principalmente en el área de turismo que es dinámico y creciente en el mundo, y aún poco explorado en América del Sur.

Palabras clave: corredor bioceánico; análisis estadístico; turismo; desafío de la ruta.

\section{INTRODUÇÃO}

A Economia do Turismo é um dos principais componentes do Produto Interno Bruto para países, regiões, estados e cidades. O comércio internacional, entre outras dimensões que compõem o Produto Interno Bruto, é alavancado também por fluxos turísticos, que impactam na integração entre povos e culturas e, principalmente, como fonte de desenvolvimento econômico e meio para criar emprego e reduzir a pobreza (SAMIMI; SADEGHI; SADEGHI, 2011; SCHUBERT; BRIDA; RISSO, 2011; ARDAHAEY, 2011; PORTO; GARBERO; ESPINOLA, 2018).

\footnotetext{
${ }^{1}$ Universidade Católica Dom Bosco (UCDB), Campo Grande, Mato Grosso do Sul, Brasil.

${ }^{2}$ Centro Universitário de Brasília (UniCEUB), Brasília-DF, Brasil.
} 
A atividade econômica do turismo nos países sul-americanos é incipiente e não integrada. $\mathrm{Na}$ Europa os países o turismo é atividade fim, que promove a integração dos fluxos comerciais de forma livre e próspera, articulando os ativos de cada território com políticas públicas que fortalecem o próprio sistema econômico. Nesse contexto, conhecer e analisar os fluxos do turismo em um Corredor que está sendo criado por iniciativa de empresários e do setor público, permite diagnosticar o estado atual de integração entre os países desse Corredor.

O objetivo deste artigo é investigar os fluxos turísticos entre os países que formam o chamado Corredor Bioceânico, isto é, Brasil, Paraguai, Argentina e Chile, analisando as receitas, as chegadas, os eventos internacionais, as formas de viagem e o fluxo em Mato Grosso do Sul, Estado brasileiro no que inicia o Corredor Bioceânico. Estudos de demanda turística remontam a década de 1980, como (LIM, 1999; SONG; LI, 2008) e na caracterização da demanda turística internacional de um grupo de países para outro (SINCLAIR; STABLER, 1995).

Para o alcance do objetivo proposto a presente pesquisa utilizou dados secundários de fonte oficiais da Organização Mundial do Turismo (OMT) e do Ministério do Turismo (MT) brasileiro. O procedimento de pesquisa é exploratório e a análise recai sobre a abordagem quantitativa, com o objetivo de investigar o panorama dos fluxos turísticos entre 1999-2017.

Este estudo revela que os fluxos do turismo são incipientes nos países do cone sul da América do Sul. O Corredor Bioceânico poderá se transformar em uma estratégia sul-americana para transformar o turismo em maior componente do PIB dos países envolvidos. As demandas nacionais e internacionais e, principalmente, de integração dependem, fortemente, da necessidade de gerar estratégias diferenciadas para promover e consolidar o turismo ao longo do Corredor Bioceânico.

Este estudo foi dividido nesta introdução, na análise macro do panorama do turismo no mundo, na seção 2, seguido da seção 2 que mostra a dinâmica do turismo na América do Sul. A Rota Bioceânica é tratada na seção 3, e logo após a análise dos resultados.

\section{PANORAMA DO TURISMO NO MUNDO}

O setor de turismo agrega aspectos econômicos, sociais, ambientais e humanos, fundamentais para o desenvolvimento das economias locais mundiais. A cadeia produtiva turística proporciona o crescimento em comunidades, municípios, regiões, estados e, em alguns países, é a principal atividade econômica.

De acordo com a Organização Mundial do Turismo, em 2017 10\% do PIB mundial foi advindo do setor de serviços turísticos. Além disso, um a cada dez empregos no mundo tem a participação do turismo. As exportações geraram U\$ 1,4 trilhões que equivale a 7\% das exportações do mundo.

Reconhecendo o turismo como um importante mercado os países procuram investir para atrair turistas, empresas, inovação e infraestrutura, para compartilhar novos potenciais turísticos dos seus ativos tangíveis e intangíveis.

A Europa atrai 50\% da demanda mundial de turistas, recebendo cerca de 615 milhões de turistas em 2017, seguida da Ásia com 25\% dos turistas, 16\% nas Américas, 5\% na África e 4\% no Oriente Médio, esses $4 \%$ equivalem a 54 milhões de turistas visitando, gastando, investindo e promovendo o Oriente Médio (OMT, 2018). 


\section{TURISMO NA AMÉRICA DO SUL}

Nas Américas os Estados Unidos da América recebem e enviam grande quantidade de turistas pelo mundo, sendo o País mais procurado das Américas. As chegadas internacionais nas Américas cresceram 7 milhões, ou seja, mais 3\% em 2016 em relação a 2015, com total de 200 milhões de turistas, equivalente a $16 \%$ do total mundial. A América do Sul cresceu $7 \%$ e liderou esse crescimento. Na última década, o turismo internacional na América do Sul cresceu, em média, de forma constante (exceto em 2009, devido à crise financeira global), com um crescimento médio anual de 7,2\% nas chegadas e 11,2\% receitas e acima da média mundial (que foi de 4,1 e 7,1\%, respectivamente) (OMT, 2018).

Os países sul-americanos que apresentaram variação positiva foram Chile (+ 26\%), Argentina (+ 15\%), Colômbia (+ 11\%), Uruguai (+ 10\%), Peru (+ 8\%) e o Brasil, o maior destino na região, apresentou um crescimento de $4 \%$ nas chegadas, após a realização dos Jogos Olímpicos e Paraolímpicos Rio em 2016, de acordo com a OMT (2018).

A receita produzida pelo turismo é um dos resultados mais importantes, pois permite conhecer os gastos dos turistas. As receitas geradas pelo turismo internacional nas Américas aumentaram 3\%, em termos reais, para US\$ 313 bilhões, ou seja, 26\% de participação no total, um aumento de US\$ 8 bilhões a partir de 2015 (OMT, 2018).

Um novo roteiro possível de turismo latino americano está sendo potencializado com a criação do Corredor Bioceânico, como parte da Rota de Integração Latino-Americana, que ligará Brasil, Paraguai, Argentina e Chile, com o objetivo principal de escoar a produção agrícola destes países para a Ásia, tornou-se uma nova possibilidade de desenvolvimento turístico da América Latina.

\section{O CORREDOR RODOVIÁRIO BIOCEÂNICO}

O Corredor Rodoviário Bioceânico é o resultado de uma aspiração de décadas alimentada por organizações privadas e públicas, principalmente pelos produtores e exportadores agrícolas que têm a América Latina e a Ásia como destino do comércio internacional. Com a assinatura da Carta de Campo Grande e da Carta de Brasília essa aspiração se transformou numa realidade, que resultou na aprovação da construção da ponte entre Brasil e Paraguai e na licitação para a construção da rodovia no Chaco paraguaio.

O objetivo inicial do Corredor Bioceânico é criar um corredor rodoviário que interligará quatro países (Brasil, Paraguai, Argentina e Chile). Com isto, no final será reduzido o tempo de deslocamento das cargas, será promovida a melhoria logística de transporte e se elevará a competitividade das exportações para a Ásia. Entre as consequências da criação do Corredor Rodoviário, acontecerá também o fomento do turismo e o estímulo à criação de novos fluxos de comércio regional e se possibilitará a integração entre estes países.

Já existe entre os países intensa relação comercial, principalmente na importação e exportação de commodities e alimentos processados. Com o Mercosul essas transações proporcionam potenciais acordos aduaneiros que podem facilitar o escoamento da produção (importação e exportação) entre os países e destes países para Ásia via Oceano Pacífico, reduzindo tempo e custos logísticos.

O Corredor Rodoviário Bioceânico se inicia em Mato Grosso do Sul (Brasil), em Campo Grande, cruzará o território paraguaio, por Carmelo Peralta, Mariscal Estigarribia e Pozo Hondo, 
atravessará no território argentino as cidades de Misión La Paz, Tartagal, Jujuy e Salta, ingressando no Chile, por Passo de Jama, até alcançar os portos de Antofagasta, Mejillones e Iquique. Esse traçado é apresentado na Figura 1, iniciando em Campo Grande.

Figura 1- Traçado da Rota Bioceânica

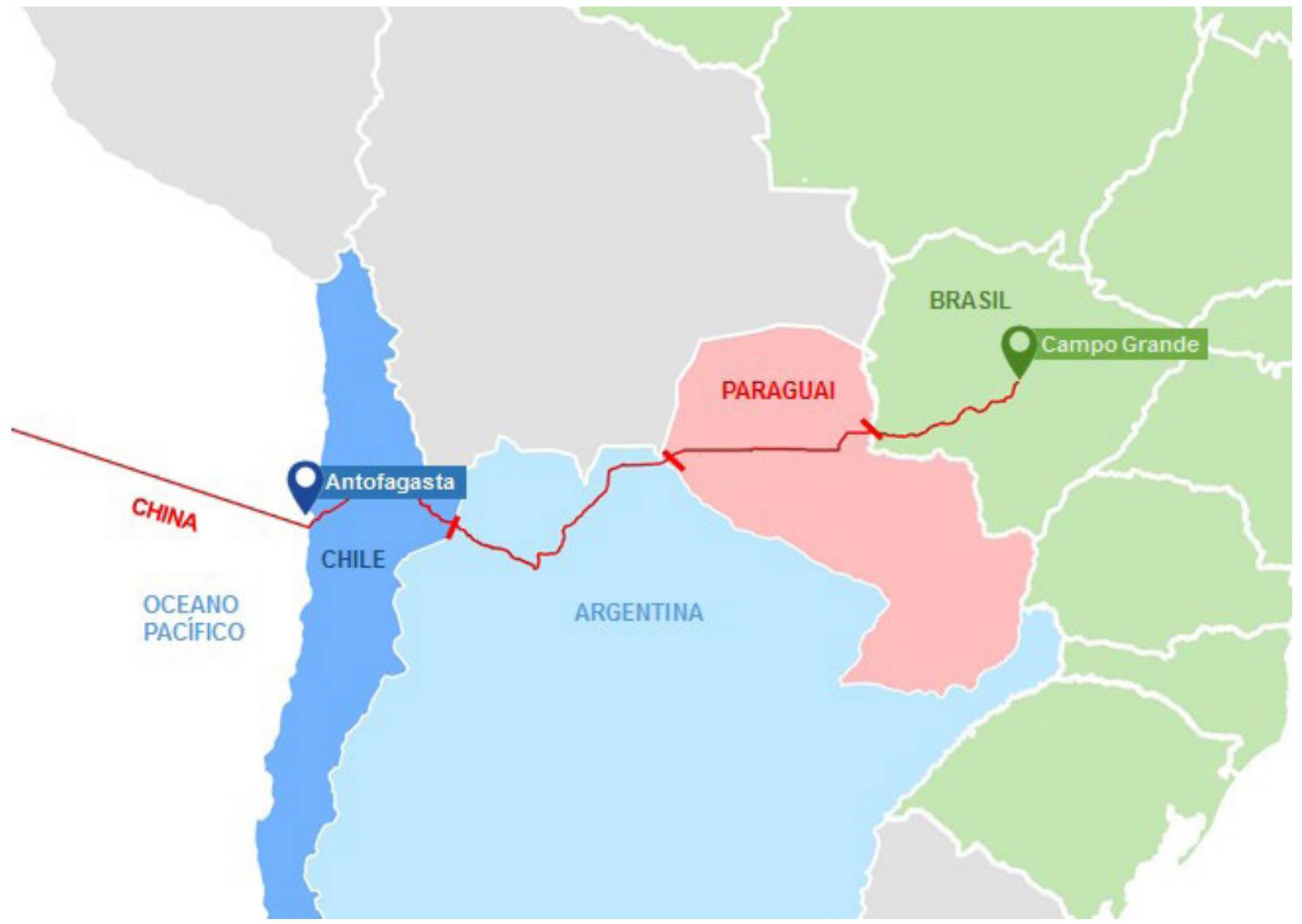

Fonte: Ministério das Relações Exteriores (CGLAC/MRE, s.d.).

Com a criação do Corredor, as externalidades produtivas podem proporcionar o desenvolvimento dos municípios ao longo da rodovia, direta e indiretamente, e principalmente fomentar a integração fronteiriça, ampliando as visitas por via terrestre aos países, municípios e atrativos da rota turística.

Neste contexto o presente estudo pretende analisar os dados de 2016 e 2017 dos fluxos turísticos entre Brasil, Argentina, Paraguai e Chile, com propósito de avaliar as demandas existentes e as relações entre os países.

\section{PROCEDIMENTOS METODOLÓGICOS}

Para o alcance do objetivo proposto o procedimento metodológico utiliza pesquisa de caráter exploratório, com abordagem e análise quantitativa, utilizando dados oficiais da Organização Mundial do Turismo e do Ministério do Turismo brasileiro para os anos de 1999 e 2017, que aplicam questionário anual sobre o turismo receptivo e emissivo internacional, além da pesquisa de demanda turística internacional.

A partir dos dados e documentos da OMT e MT a análise inicial pretende explorar os dados mundiais e da América Latina, além da análise específica que tem como objetos de estudo os quatro países que 
compõem o Corredor Bioceânico, que é um dos elementos da Rota de Integração Latino-Americana, com o objetivo de revelar os fluxos turísticos e suas demandas.

\section{RESULTADOS}

O turismo no mundo tem um comportamento exponencial. Sua receita, de acordo com dados da OMT (2018), vem crescendo de 1999 a 2017. A variação média entres estes anos foi em torno de 5,75\%, com variações negativas apenas entre os anos 2000-2001; 2008-2009 e 2014-2015. Porém, de 2016 para 2017, a variação positiva da receita foi de 7,51\%.

Figura 2 - Receita mundial da atividade turística, em bilhões US\$

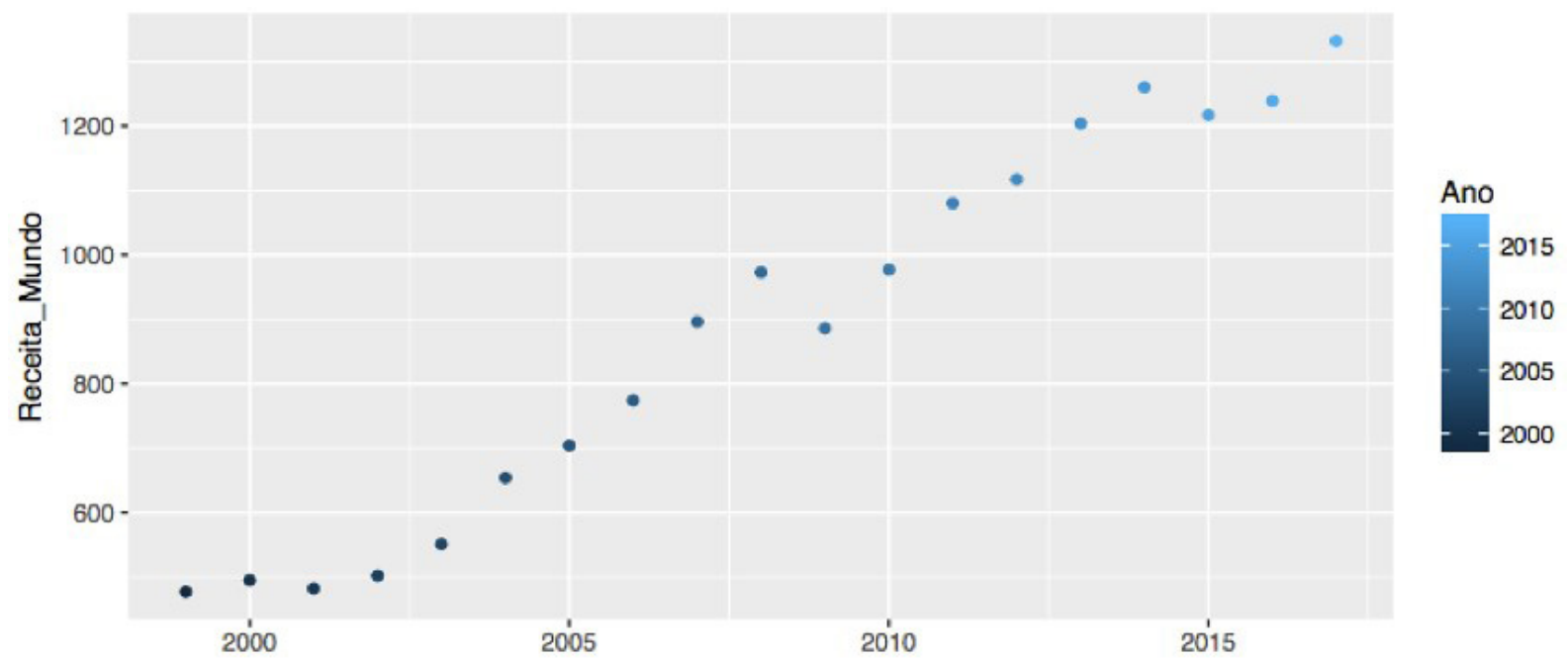

Fonte: OMT (2018).

A Figura 2 apresenta este comportamento exponencial. Visualmente é possível acompanhar o efeito negativo da crise financeira mundial entre 2008-2009 e o crescimento entre 2016-2017. Este, de acordo com a OMT (2018), foi o efeito dos chineses no mercado mundial, ajudando a fechar a receita de mais de US\$1,3 trilhões no mundo.

Na América do Sul não foi diferente. Os resultados acompanham a onda mundial, com crescimento exponencial, porém numa escala bem menor. A Figura 3 apresenta a receita da América do Sul entre 1999-2017 considerando os valores em dólares. Apesar das crises econômicas no Brasil e na Argentina, desde 2010 o turismo se manteve em crescimento e, nos anos de 2016-2017, tiveram alto crescimento. 
Figura 3- Receita da atividade turística para a América do Sul, em bilhões US\$

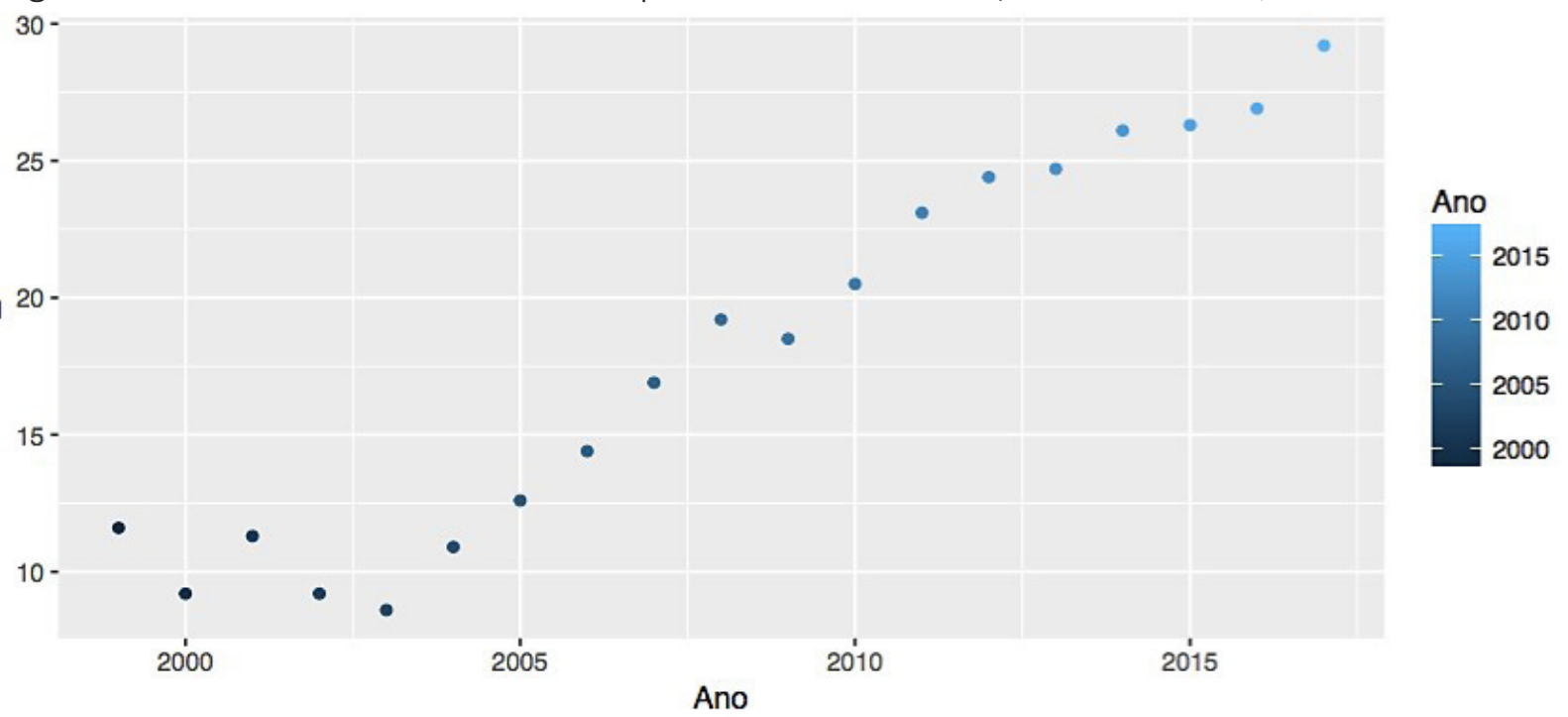

Fonte: OMT (2018).

Com receitas, em 2017, perto de US\$ 30 bilhões, precisamente US\$29,2 bilhões, a América do Sul apresenta alto potencial de crescimento dentro do grande mercado mundial de turismo. A participação da América do Sul em relação à receita mundial tem média em torno de $2 \%$, de 1999 a 2017.

Figura 4- Taxa de Participação da Receita da América do Sul no Mundo, em \%

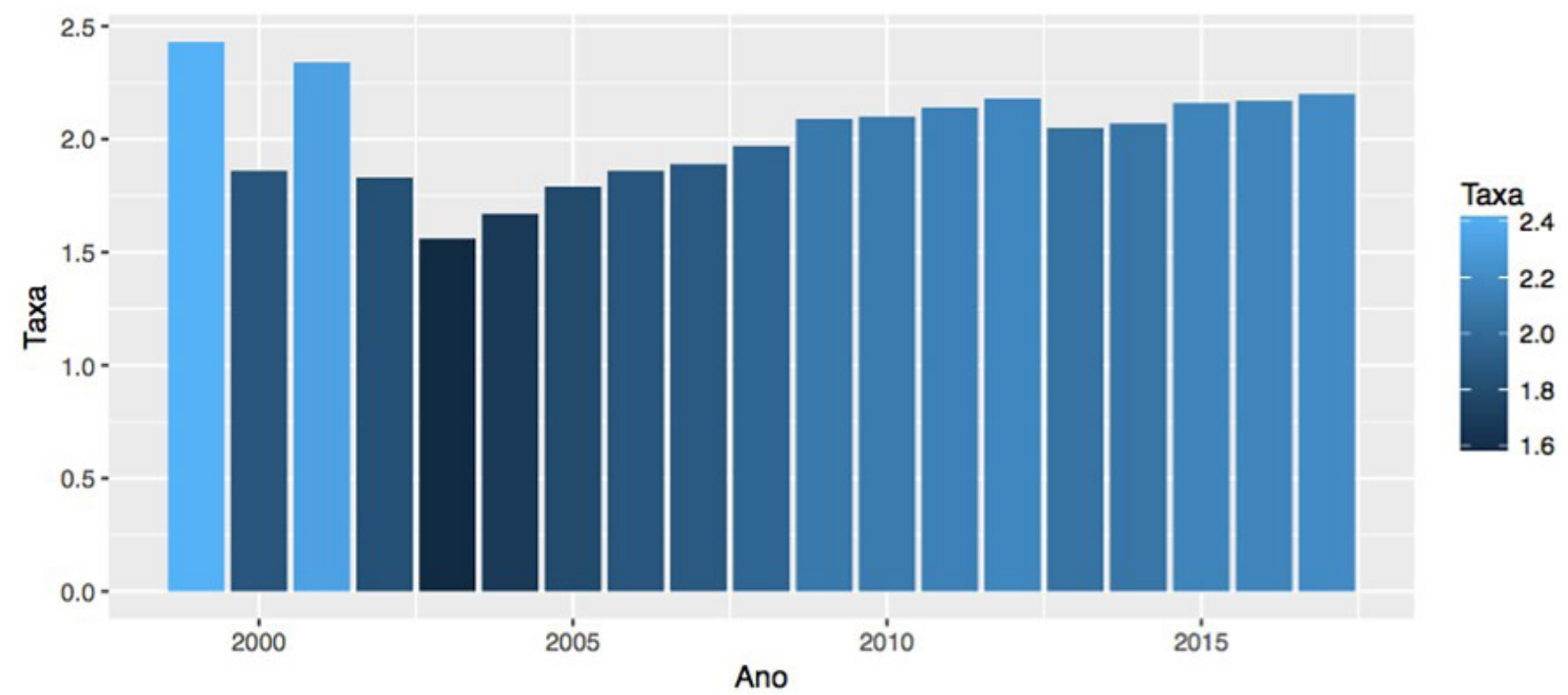

Fonte: OMT (2018).

A taxa de participação, calculada com os dados da OMT (2018), mostra que a variação segue uma média em torno de $2 \%$ e os países sul-americanos não têm aproveitado o crescimento do turismo no mundo para aumentar sua participação ao longo do tempo. Os dados apresentam evidências de que, nos anos de 1999 e 2001, a taxa de participação era maior que a atual. 
Figura 5 - Chegadas de Turistas no Mundo e na América do Sul
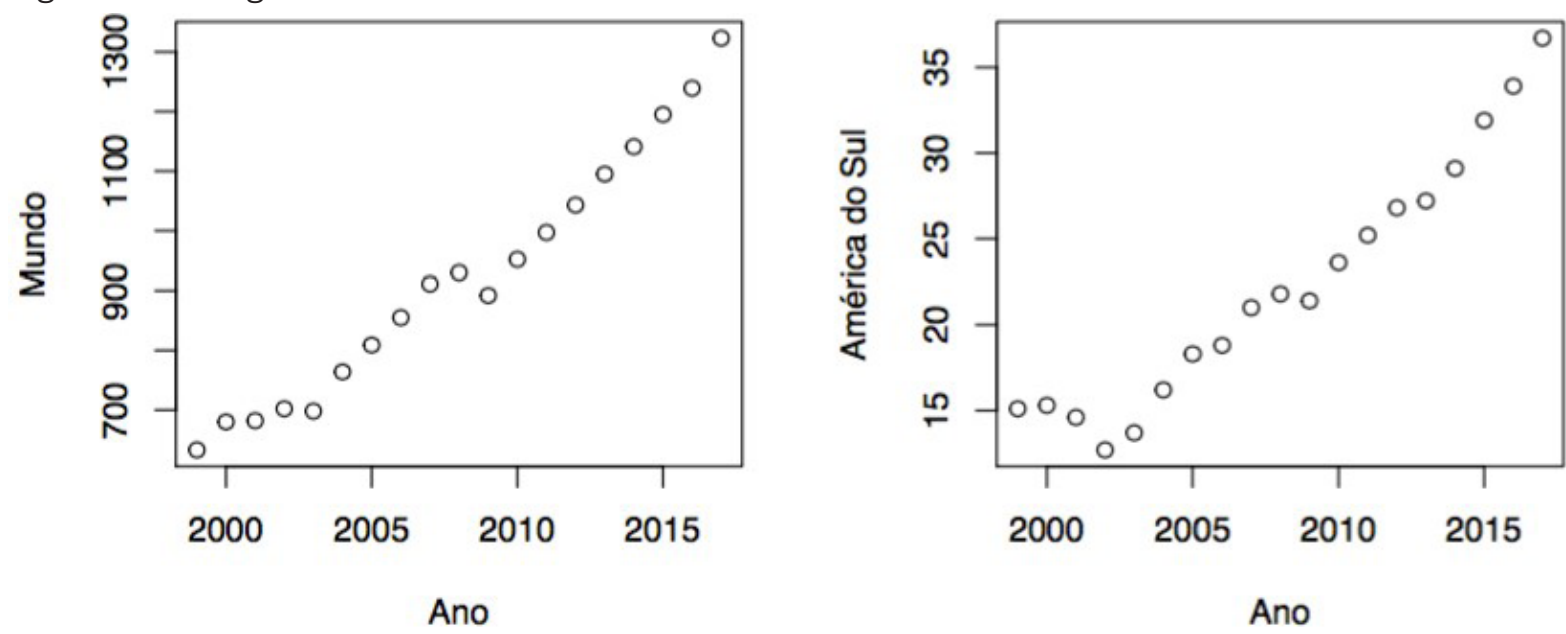

Fonte: Brasil, 2018.

Um indicador muito utilizado pela literatura especializada e pelos órgãos governamentais é o número de chegadas de turistas. A Figura 5 apresenta o resultado do número de chegadas de turistas entre 1999-2017, no mundo e na América do Sul. Esses dados, quando comparados, possibilitam inferir inferir que o comportamento ao longo do tempo é semelhante, porém em escalas de valores bem distintas. Novamente apresentando uma oportunidade de aumentar o Market-Share da América do Sul.

\subsection{Análise da América do Sul e países do Corredor Bioceânico}

Com o intuito de analisar a integração existente entre os países do Corredor Bioceânico, parte a Rota de Integração Latino Americana (Rila), no tocante ao fluxo turístico, o Quadro 1 apresenta as chegadas de turistas ao Brasil por residentes da América do Sul e em destaque os países do Corredor Bioceânico, isto é, da Argentina, do Chile e do Paraguai.

Os argentinos representam a maior demanda no total de turistas que foram ao Brasil, com cerca de 64\% em 2017, e também no total por via de acesso, seja aérea, terrestre, marítima ou fluvial (BRASIL, 2018), enquanto que Chile e Paraguai representam 8\% do total em 2017 das chegadas no Brasil, conforme Quadro 1.

No Quadro 1 destaca-se que as chegadas de turistas entre 2016 e 2017 sempre tiveram aumento entre os países do Corredor Bioceânico. Levando em conta as crises econômicas de Brasil e Argentina desde 2010, os números revelam que a atividade econômica turismo é um dos serviços que podem incrementar o crescimento dos países e fortalecer o Produto Interno Bruto, provocando externalidades positivas na renda, emprego e redução da pobreza, como afirmam Samimi, Sadeghi e Sadeghi (2011), Schubert, Brida e Risso (2011) e Ardahaey (2011). 
Quadro 1 - Chegadas de Turistas no Brasil por residentes da América do Sul e por via

\begin{tabular}{|c|c|c|c|c|c|c|c|c|c|c|c|c|c|c|c|}
\hline & \multicolumn{2}{|c|}{ Total } & & \multicolumn{2}{|c|}{ Aérea } & & \multicolumn{2}{|c|}{ Terrestre } & & \multicolumn{2}{|c|}{ Marítima } & & \multicolumn{2}{|c|}{ Fluvial } & \\
\hline & 2016 & 2017 & $\%$ & 2016 & 2017 & $\%$ & 2016 & 2017 & $\%$ & 2016 & 2017 & $\%$ & 2016 & 2017 & $\%$ \\
\hline Argentina & 2294900 & 2622327 & 64 & 1037055 & 1148044 & 57 & 1173431 & 1381992 & 69 & 11401 & 23609 & 95 & 73013 & 68682 & 94 \\
\hline Bolívia & 138106 & 126781 & 3 & 76446 & 59307 & 3 & 61617 & 67407 & 3 & 14 & 22 & 0 & 29 & 45 & 0 \\
\hline Chile & 311813 & 342143 & 8 & 296073 & 324098 & 16 & 15437 & 17600 & 1 & 277 & 402 & 2 & 26 & 43 & 0 \\
\hline Colômbia & 135192 & 140363 & 3 & 116542 & 123791 & 6 & 18488 & 16354 & 1 & 53 & 131 & 1 & 109 & 87 & 0 \\
\hline Equador & 0604 & 34244 & 1 & 25158 & 28300 & 1 & 5425 & 5881 & 0 & 13 & 47 & 0 & 8 & 16 & 0 \\
\hline Guiana & 5289 & 5038 & 0 & 474 & 649 & 0 & 4788 & 4355 & 0 & 2 & 1 & 0 & 25 & 33 & 0 \\
\hline G. Francesa & 8 & 1321 & 0 & 8 & 1320 & 0 & 0 & 0 & 0 & 0 & 0 & 0 & 0 & 1 & 0 \\
\hline Paraguai & 316714 & 336646 & 8 & 50808 & 60690 & 3 & 261592 & 271933 & 13 & 19 & 68 & 0 & 4295 & 3955 & 5 \\
\hline Peru & 114276 & 115320 & 3 & 85706 & 85427 & 4 & 28330 & 29577 & 1 & 36 & 55 & 0 & 204 & 261 & 0 \\
\hline Suriname & 9169 & 6096 & 0 & 9035 & 5944 & 0 & 113 & 121 & 0 & 0 & 0 & 0 & 21 & 31 & 0 \\
\hline Uruguai & 284113 & 328098 & 8 & 117797 & 132727 & 7 & 165731 & 194564 & 10 & 422 & 589 & 2 & 163 & 218 & 0 \\
\hline Venezuela & 61160 & 53950 & 1 & 34470 & 26372 & 1 & 26634 & 27480 & 1 & 23 & 36 & 0 & 33 & 62 & 0 \\
\hline Total & 3701344 & 4112327 & & 1849572 & 1996669 & & 1761586 & 2017264 & & 12260 & 24960 & & 77926 & 73434 & \\
\hline
\end{tabular}

Fonte: Brasil (2018).

De acordo com o Ministério do Turismo do Brasil (BRASIL, 2018), os Argentinos visitam o Brasil principalmente as cidades de Florianópolis, em Santa Catarina, e Foz do Iguaçu, no Paraná, com o objetivo de lazer. Neste Quadro 1 a integração entre os países do Corredor Bioceânico e também os demais países da América do Sul é ainda um desafio para o desenvolvimento do turismo. O estudo do Ministério de Turismo (BRASIL, 2018) os países que mais enviaram turistas para o Brasil em 2017 foram a Argentina, seguido dos Estados Unidos. Em terceiro lugar fica o Chile e em quarto o Paraguai.

Uma das variáveis analisadas é a quantidade de eventos internacionais que os países oferecem. Esses eventos em geral atraem turistas em todo o mundo, seja para negócios, seja para estudos, seja para convenções, entre outros motivos. De acordo com dados do Ministério do Turismo brasileiro (BRASIL, 2018), com relação às viagens motivadas por negócios, eventos e convenções, o acesso por via aérea é predominante entre seus principais destinos, e o gasto per capita também é maior em relação ao lazer ou outro motivo da viagem.

A análise da quantidade de eventos internacionais pelas principais cidades-países que tenham impacto significativo no turismo mundial e apareçam nas estatísticas da Organização Mundial do Turismo, foi realizada na Figura 6 que contemplam os países do Corredor Bioceânico e os dados mundiais.

Figura 6 - Quantidade eventos internacionais por cidades-países e mundo
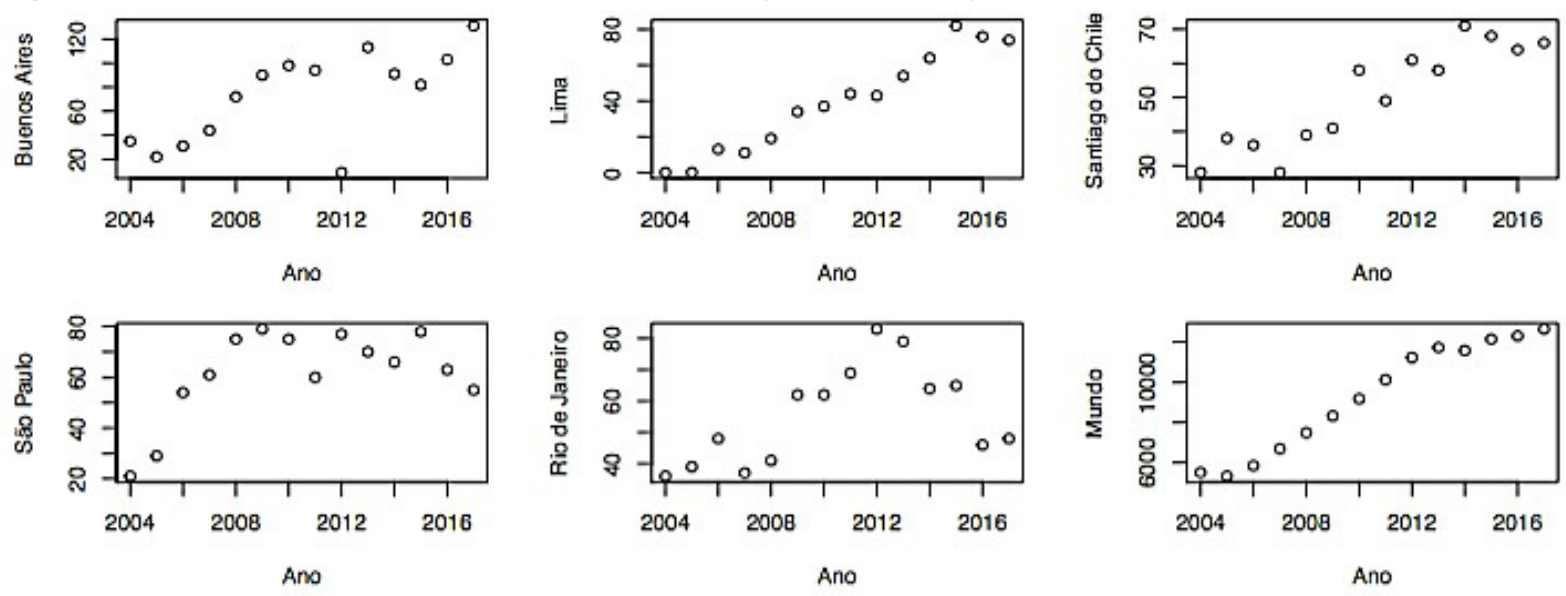

Fonte: OMT (2018). 
Em algumas cidades, como Buenos Aires, São Paulo e Rio de Janeiro, o comportamento de quantidade de eventos é aleatório, com tendência positiva. Na capital peruana e na capital chilena há um comportamento de crescimento positivo ao longo dos anos, mesmo comportamento de eventos no mundo.

\subsection{Países do Corredor Bioceânico e Mato Grosso do Sul}

O movimento de criação do Corredor Rodoviário Bioceânico, fruto da criação da Rota de Integração Latino-Americana, partiu das iniciativas de empresários de Mato Grosso do Sul. Observando o gargalo de exportação de commodities pelos portos brasileiros e por outro lado o aumento da demanda de alimentos pela China e da Índia, os empresários se reuniram com gestores públicos para buscar alternativas para a viabilizar o transporte de produtos pelo Oceano Pacífico.

A Figura 1 apresenta a partida do Corredor Rodoviário Bioceânico de Mato Grosso do Sul. Trata-se de um Corredor de integração pelo qual se pretende exportar e importar produtos. No tocante ao turismo, Mato Grosso do Sul é lembrado mundialmente pela natureza do Pantanal, juntamente com Mato Grosso, e pela cidade de Bonito. Neste contexto esta análise recai sobre as chegadas de turistas ao Brasil via Mato Grosso do Sul. A fronteira terrestre terá uma nova passagem com a construção da ponte entre Porto Murtinho, no Brasil, e Carmelo Peralta, no Paraguai.

Quadro 2 - Chegadas de Turistas no Brasil pelo Mato Grosso do Sul da América do Sul

\begin{tabular}{|c|c|c|c|c|c|c|c|c|c|c|}
\hline \multirow{4}{*}{$\begin{array}{c}\text { América do } \\
\text { Sul }\end{array}$} & \multicolumn{10}{|c|}{ Chegadas de turistas pelo Mato Grosso do Sul } \\
\hline & \multirow{2}{*}{\multicolumn{2}{|c|}{ Total }} & \multicolumn{8}{|c|}{ Vias de acesso } \\
\hline & & & \multicolumn{2}{|c|}{ Aérea } & \multicolumn{2}{|c|}{ Terrestre } & \multicolumn{2}{|c|}{ Marítima } & \multicolumn{2}{|c|}{ Fluvial } \\
\hline & 2016 & 2017 & 2016 & 2017 & 2016 & 2017 & 2016 & 2017 & 2016 & 2017 \\
\hline Argentina & 1528 & 1031 & 25 & 4 & 1503 & 1027 & - & - & 0 & 0 \\
\hline Bolívia & 42111 & 48817 & 66 & 21 & 42038 & 48794 & - & - & 7 & 2 \\
\hline Chile & 544 & 331 & 1 & 0 & 543 & 331 & - & - & 0 & 0 \\
\hline Colômbia & 604 & 620 & 1 & 0 & 601 & 620 & - & - & 2 & 0 \\
\hline Equador & 188 & 267 & 1 & 0 & 187 & 267 & - & - & 0 & 0 \\
\hline Guiana & 0 & 0 & 0 & 0 & 0 & 0 & - & - & 0 & 0 \\
\hline G. Francesa & 0 & 0 & 0 & 0 & 0 & 0 & - & - & 0 & 0 \\
\hline Paraguai & 25627 & 24588 & 93 & 39 & 25228 & 24461 & - & - & 306 & 88 \\
\hline Peru & 1788 & 1211 & 0 & 2 & 1788 & 1209 & - & - & 0 & 0 \\
\hline Suriname & 0 & 0 & 0 & 0 & 0 & 0 & - & - & 0 & 0 \\
\hline Uruguai & 67 & 61 & 7 & 0 & 60 & 61 & - & - & 0 & 0 \\
\hline Venezuela & 72 & 94 & 0 & 0 & 72 & 94 & - & - & 0 & 0 \\
\hline Total & 72529 & 77020 & 194 & 66 & 72020 & 76864 & - & - & 315 & 90 \\
\hline
\end{tabular}

Fonte: Ministério do Turismo (BRASIL, 2018).

Os dados do Ministério do Turismo (BRASIL, 2018) comprovam que em 2016 e 2017 a relação existente entre os países do Corredor Bioceânico e Mato Grosso do Sul é incipiente e relativamente pequena. Com exceção ao Paraguai, que já se criou uma integração entre as cidades de Ponta Porã e Pedro Juan Cabalero no comércio, na cultura, na gastronomia e no livre comércio entre as cidades, os demais países têm poucas chegadas nesta fronteira e que no total diminuiu entre 2016 e 2017, para os países do Corredor Bioceânico. 


\section{CONSIDERAÇÕES FINAIS}

O desenvolvimento de um corredor logístico entre quatro países e com objetivo de ligar um oceano ao outro é um grande desafio. Prevendo o aumento dos gargalos relacionados com o escoamento da produção de commodities, o Brasil empreendeu, a partir de empresários e gestores públicos, uma proposta conjunta com a Argentina, Chile e Paraguai para a construção De um Corredor Rodoviário Bioceânico que transcendeu ao objetivo principal e proporcionará, no fim, a verdadeira integração entre os países.

Nasceu então a ideia de integração dos países sul-americanos para a criação da rota turística, devido à proximidade, à afinidade, às potencialidades e principalmente à possibilidade de desenvolvimento econômico dos países. Porém o setor turístico é uma iniciativa que engloba as atividades econômica, sociais, ambientais, entre outros aspectos do desenvolvimento.

Neste contexto foi analisada a integração entre os países a partir dos fluxos do turismo. A partir de abordagem quantitativa o presente estudo apresentou as fragilidades nas relações turísticas entre os países do Corredor Rodoviário Bioceânico, com pouco fluxo e integração incipiente.

O presente estudo apresentou o Panorama Geral do turismo entre os países do Corredor Bioceânico. Novos estudos poderão avaliar esse panorama após a construção da ponte entre Brasil e Paraguai, que poderá ser um marco no desenvolvimento destes países e do setor turístico.

\section{REFERÊNCIAS}

ARDAHAEY, F.T. Economic impacts of tourism industry. International Journal of Business and Management, v. 6, n. 8, p. 206-15, 2011.

LIM, C. A Meta analysis review of international tourism demand. Journal of Travel Research, v. 37, n. 3, p. 273-84, 1999.

BRASIL. Ministério das Relações Exteriores (CGLAC/MRE). Brasília-DF, [s.d.]. Disponível em: http://www. itamaraty.gov.br/. Acesso em: 10 out. 2018

BRASIL. Ministério do Turismo. Dados e fatos. Brasília, 2018. Disponível em: http://dadosefatos.turismo. gov.br/2016-02-04-11-53-05.html. Acesso em: 10 out. 2018

WORLD TOURISM ORGANIZATION (OMT). UNWTO World Tourism Barometer. World Tourism Organization, 2018.

PORTO, N.; GARBERO, N.; ESPINOLA, N. Spatial distribution of touristic flows in a gravity model in South America. Journal of Tourism Analysis: Revista de Análisis Turístico, v. 25, n. 1, p.39-53, 2018. Disponível em: https://doi.org/10.1108/JTA-02-2018-0005. Acesso em: 15 out. 2018

SAMIMI, A. J.; SADEGHI, S.; SADEGHI, S. Tourism and economic growth in developing countries: P-VAR approach. Middle-East Journal of Scientific Research, v. 10, n. 1, p. 28-32, 2011.

SCHUBERT, S. F.; BRIDA, J. G.; RISSO, W. A. The impacts of international tourism demand on economic growth of small economies dependent on tourism. Tourism Management, v. 32, n. 2, p. 377-85, 2011.

SINCLAIR, M. T.; STABLER, M. The Economics of Tourism. New York: Routledge Advances in Tourism Series; University of Reading, 1995.

SONG, H.; LI, G. Tourism demand modeling and forecasting: a review of recent research, Tourism Management, v. 29, n. 2, p. 203-20, 2008. 


\section{Sobre os autores:}

Michel Constantino - Doutor em Economia pela Universidade de Brasília. Vice-Coordenador do Programa de Pós-Graduação em Desenvolvimento Local da Universidade Católica Dom Bosco - Mestrado e Doutorado, Campo Grande, MS. E-mail: michelangelo111@gmail.com, Orcid: http://orcid.org/0000-0003-2570-0209

Arlinda Cantero Dorsa - Doutora em Língua Portuguesa pela PUC-SP. Coordenadora do Programa de Pos-Graduação em Desenvolvimento Local da Universidade Católica Dom Bosco - Mestrado e Doutorado, Campo Grande, MS. E-mail: acdorsa@ucdb.br, Orcid: http://orcid.org/0000-0003-0957-9779

João Carlos Medeiros de Aragão - Doutor em Direito Constitucional, pela Pontifícia Universidade Católica de São Paulo. Mestrado em Direito das Relações Internacionais pelo Centro Universitário de Brasília. Pós-Graduação lato sensu em Advocacia na Instância Superior, em Linguística do Texto e em Metodologia do Ensino Jurídico. Graduação em Direito, em Letras e em Pedagogia. Membro do Instituto dos Advogados do Distrito Federal, da Rede de Excelência Jurídica, Centro Brasileiro de Estudos Constitucionais e da Associação Brasiliense de Processo Civil. E-mail: joao.aragao@camara.leg.br, Orcid: http://orcid.org/0000-0003-1210-6614

Dany Rafael Fonseca Mendes - Mestre em Análise Econômica do Direito pela Universidade Católica de Brasília (UCB). Bacharel em Direito pela Universidade Federal de Ouro Preto (UFOP). Consultor (OAB/DF 36620), professor Adjunto do UniCEUB e Pesquisador (ResearchGate Score 10.56), com participação em vários grupos/projetos de pesquisa e atuação em diversos periódicos, para os quais já produziu mais de uma centena de pareceres "blind review". E-mail: rafael.dany@gmail.com, Orcid: http://orcid.org/0000-0002-2504-3272 
